\title{
Educating the Infection Prevention \& Control Educators - Musings from the IFIC Education Chair
}

\author{
Gayle Gilmore \\ Chair of IFIC Education committee
}

doi: 10.3396/ijic.V7i2.010.11

Welcome to IJIC's journal with special emphasis on education. As you will read in various papers in this journal, the education and training of healthcare professionals is a priority around the world. Education and training is also a priority of the International Federation of Infection Control (IFIC). In the rapidly changing world of infection prevention and control, education continues to be the best method of decreasing the risk of infections. As an overview, this paper will review adult education and discuss several methods that may be applicable in your educational efforts.

The training and education of adults is different from childhood education; this has been recognized for centuries and was first called andragogy, (Greek for 'man-leading'), in 1833 by Alexander Kapp, a German educator. Pedagogy, (Greek for 'child-leading'), refers to the education of children.

In the mid-1900s, Malcolm Knowles expanded on the process of learning strategies specifically for adults, and he is generally accepted as the Father of
Adult Education. Andragogy includes the process of involving adult learners into the structure of the learning experience itself. Adults will learn only after becoming self-convinced of the need to learn, selfmotivated to participate in learning, and self-directed to seek new skills/behaviors/attitudes. The role of the educator is minimized and the teacher becomes more of a facilitator for learning. If an adult fails to learn, it is not assumed that the instructor has failed.

There are six major motivational assumptions in Knowles learning theory:

1. Need to know. Adults need to know the reason for learning something. If your hospital is instituting a more restrictive antibiotic formulary within the next month, practitioners will have questions and comments regarding the changes. Were you fully attentive at the first lecture on HIV/AIDS? Or did you assume that process would never affect your practice?

2. Foundation. Experience, including errors, provides the basis for learning activities. Every error should be seen as a learning opportunity, and education is

\footnotetext{
Corresponding author

Gayle Gilmore

Infection Control Education and Consultation

Email: ggilmore217@gmail.com
} 
the basic element of ensuring that similar error will not occur again. The more severe the incident, the more staff will be eager for additional practice and training. More experienced practitioners have their history as a gridwork foundation for meeting new challenging conditions.

3. Self-concept. Adults need to be responsible for their decisions on education; involved in the planning and evaluation of their instruction. For example, if there is a problem with turnaround time for cleaning and sterilization of equipment for a department, the personnel in that department are best able to find solutions. A multi-disciplinary team could revise procedures, discuss methods of instruction, and be involved in the teaching or hands-on practice. An evaluation of the instruction is useful at the end of the class and also as followup to monitor change in practice.

4. Readiness. Adults are most interested in learning subjects having immediate relevance to their work and/or personal lives. If a patient develops a clostridium infection in an intensive care unit, the staff becomes interested and willing to learn!

5. Orientation. Adult learning is problem-centered, rather than content-oriented. For example, a case study on a patient with an infectious disease will generate more discussion and consensus than a lecture only on the same disease.

6. Motivation. Adults respond better to internal versus external motivators. No matter how we as infection control professionals want every staff member to follow good hygiene practices, our ability to force a change in practice is very limited. Our role is more to encourage and reward a change in practice.

David Kolb expanded on Malcolm Knowles theory and asserted that adult learners by nature, are practical learners and need to see rapid application of their learning. To ensure this rapid application, the adult educator must understand 1) the basics of the work; 2) the work environment; and 3) the challenges facing the adults engaged in that work. Kolb further proposes that adults learn through reflective observation, abstract conceptualization, active experimentation, and concrete experience. In planning adult education, each of these learning styles should be included in a successful adult learning program.
Another aspect of adult education frequently in the literature is the use of humor in educational programs. According to Ron Dieter, Professor of Economics at lowa State University, physiological benefits of humor include muscle relaxation, stimulated circulation, improved respiration, and exercise of the lungs and chest muscles, increased production of the body's natural pain killers called endorphins, as well as lowered pulse rate and blood pressure, reduced anxiety and stress, greater self-esteem, and increased self-motivation (www.celt.iastate.edu/newsletter/ v11n2/humor.html). "Also, it is physically impossible to laugh and snore at the same time" (Berk RA. Professors are From Mars, Students are From Snickers. Madison, WI: Mendota Press.1998).

The primary reason for using humor in education is to improve student learning. The use of humor should be a teaching tool that will have many positive benefits, such as breaking down barriers and building rapport between student and teachers; improving retention of new material; improving the chance of students attending a class!; decreasing confrontational attitudes, and a decreased boredom quotient.

"One final benefit I will suggest, primarily from the instructor's perspective, is that an instructor who effectively prepares and uses humor in the classroom will find that teaching is more fun and enjoyable. Trying to achieve excellence in how to teach, whether it be with humor or with something else, requires creativity and can bring some of the challenges back to teaching for those who may have lost it because they have mastered the what to teach. Watching students who you know are enjoying listening to you (or at least staying awake) and hearing them laugh at your humor is very rewarding" (www.celt.iastate.edu/newsletter/ v11n2/humor.html).

Does this humor information apply to you? Who was your favorite teacher in college? Which presentations from the last conference you attended do you remember? Or more importantly, what information do you quickly remember from the conference? Did the instructor use humor? If so, might you need to add a bit more humor to your presentations? 
"Real education must ultimately be limited to men who insist on knowing, the rest is mere sheep-herding" (Ezra Pound). "Education is simply the soul of a society as it passes from one generation to another" (G.K. Chesterton). "Teachers open the door. You enter by yourself" (Chinese Proverb). "One must learn by doing the thing; for though you think you know it, you have no certainty, until you try" (Sophocles). 